\title{
Moving Targets: Assessing Fraser River Pink Salmon Run Size during a Period of Change and Uncertainty
}

\author{
Merran J. Hague ${ }^{1}$, Rachael L. Hornsby ${ }^{1}$, Jessica A. Gill ${ }^{1}$, Catherine G.J. Michielsens ${ }^{1}$, Erica S. Jenkins ${ }^{2}$, and \\ Serena Wong ${ }^{1}$
}

${ }^{1}$ Pacific Salmon Commission, 600-1155 Robson Street, Vancouver, BC, Canada

${ }^{2}$ Ministry of Forests, Lands, Natural Resource Operations, and Rural Development, Victoria, BC, Canada

Keywords: Fraser River, pink salmon, Pacific Salmon Commission, stock assessment, run reconstruction

The Pacific Salmon Commission (PSC) is a regional fisheries management organization established in 1985 by Canada and the United States as the body responsible for upholding the terms of the Pacific Salmon Treaty (PSC 2019a). The mandate of the Treaty is to ensure the two Parties share responsibility for the management, research, and enhancement of salmon stocks of mutual concern to maximize optimal production and to allocate harvests relative to the production of salmon in each country. The PSC Secretariat helps administrate the implementation of Treaty obligations and supports the intense in-season management schedules for Fraser River sockeye (Oncorhynchus nerka) and pink (Oncorhynchus gorbuscha) salmon (https://www.psc.org). Biological staff manage test fisheries, collect and analyze DNA samples for stock identification, operate a hydroacoustic program in the lower Fraser River (e.g., PSC 2021; Fig. 1), and update stock assessments throughout the fishing season. Despite representing one of the most data-rich and most intensely managed salmon fisheries in the Pacific, accurately estimating the return of pink salmon, in a timely manner for making fisheries management decisions, continues to be a challenge. Recent changes to the productivity (DFO 2021) and migration behaviour (Folkes et al. 2018) of the pink salmon run has confounded in-season assessments, leading biologists to review and update their traditional suite of stock assessment tools with the aim of improving the accuracy of run size and timing estimates.

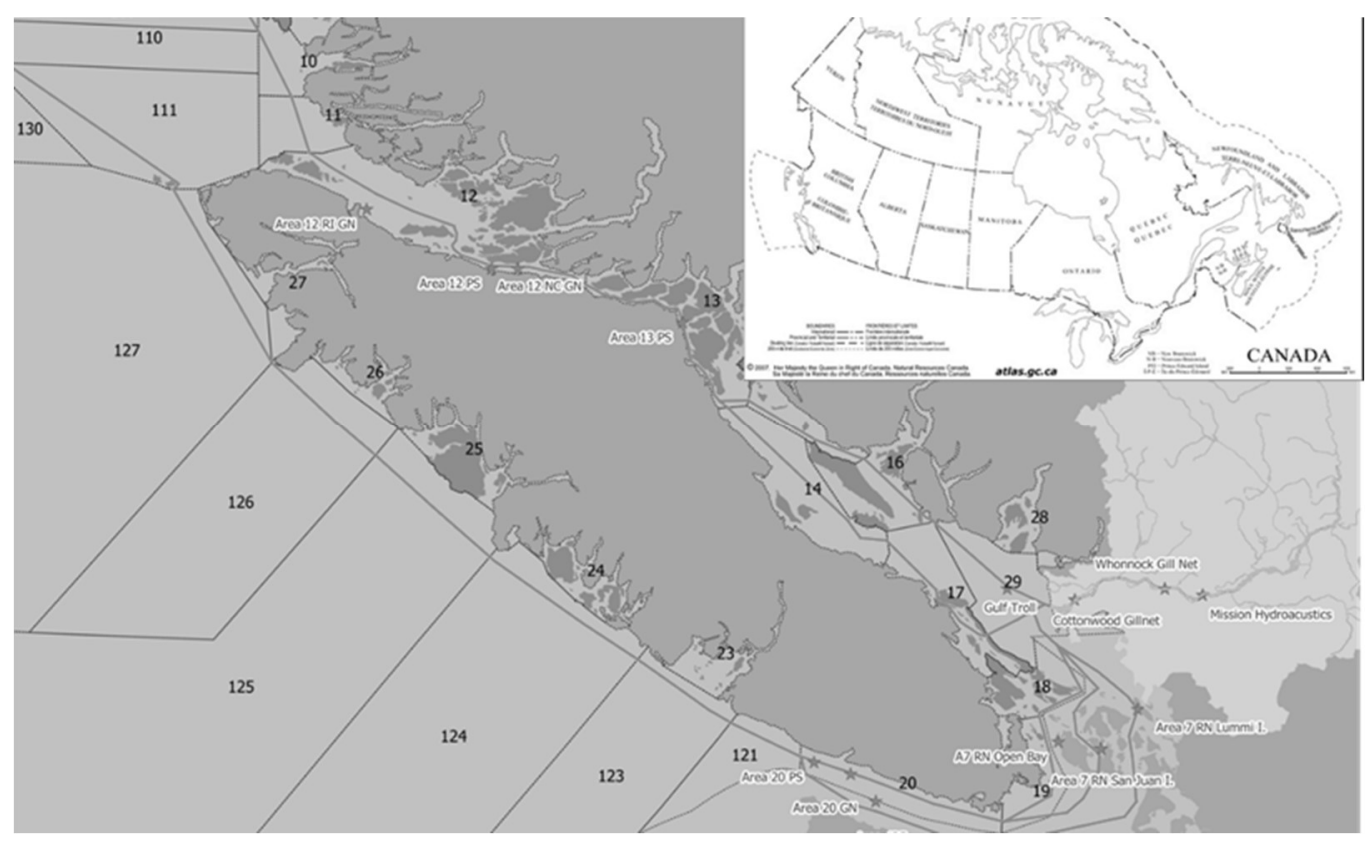

Fig. 1. A map of key fishing and assessment locations for Fraser River sockeye and pink salmon managed under the terms of the Pacific Salmon Treaty in British Columbia, Canada and Washington, U.S.A.

Pink salmon return to the Fraser River on an odd-year cycle (Heard 1991), typically with peak arrival timing in marine approach fisheries at the southern and northern ends of Vancouver Island (Fig. 1) occurring in the third week of August (PSC 2021). Many of the assessment tools originally developed for sockeye salmon do not perform well for pink salmon due to slower and more variable migration speeds. In addition to small and highly variable catchability coefficients associated with pink salmon catches in marine test fisheries, bias in assumed marine timing, migration behaviour, and run size priors have also contributed more frequently to assessment errors in recent years.

Similar to many other Pacific salmon populations (Dorner et al. 2008; Kovach et al. 2012), Fraser River pink salmon have demonstrated both non-stationarity and/or increased variability in both productivity (DFO 2021) and migration behaviour (Fig. 2) over the last 20 years. These changes are not surprising considering the observed 
trends in several oceanographic variables (e.g., sea surface temperature (SST), Pacific decadal oscillation (PDO), North Pacific gyre oscillation (NPGO)) over the same time frame (e.g., Agha et al. 2021; Crozier et al. 2021; Litzow et al. 2018), and a recognition that characteristics of Pacific salmon returns will often co-vary with environmental data (Beamish et al. 1999; Peterman and Dorner 2012; Connors et al. 2020). As a result, there is greater uncertainty in pre-season assumptions and priors that are used to parameterize in-season stock assessment tools. In response, both DFO and PSC biologists have recently revised their data sources and models used for both pre-season forecasts and in-season assessments of Fraser River pink salmon.
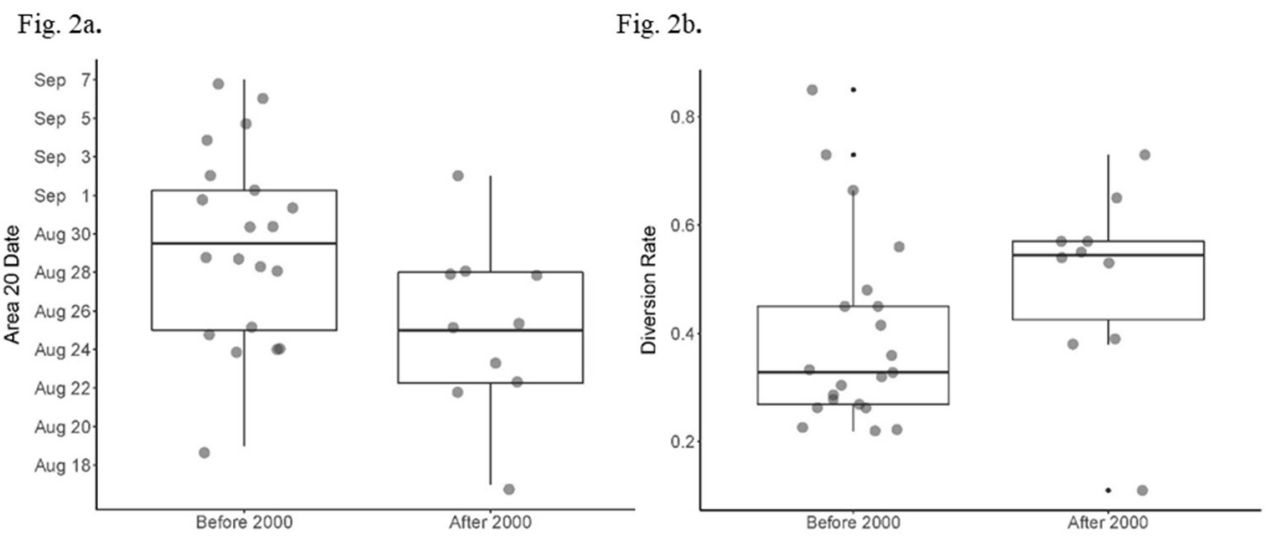

Fig. 2. Box-plots comparing the marine timing of pink salmon in years before and after 2000 (a) and percent diversion around the northern versus southern end of Vancouver Island (b). Marine timing is indexed to arrival at a purse seine test fishery located on the southwest coast of Vancouver Island (Fig. 1). Data are from 1959-2019.

Two approaches have been explored to improve the information in pink salmon pre-season priors. The first approach constrains the historical dataset to a reduced number of years, both for model fitting and for generating prior distributions. Given the non-stationarity in the time series of timing and northern diversion (the percentage of the return anticipated to migrate around the northern tip of Vancouver Island en route to the Strait of Georgia; Folkes et al. 2018), initial pre-season estimates provided to fisheries managers in 2021 were based on a reduced subset of historical data from 2001-2019 (Fig. 2). Other salmon scientists have noted correlations between environmental regime shifts and aspects of salmon biology (e.g., Beamish et al. 1999) and acknowledge that older historical data may not be representative of current conditions.

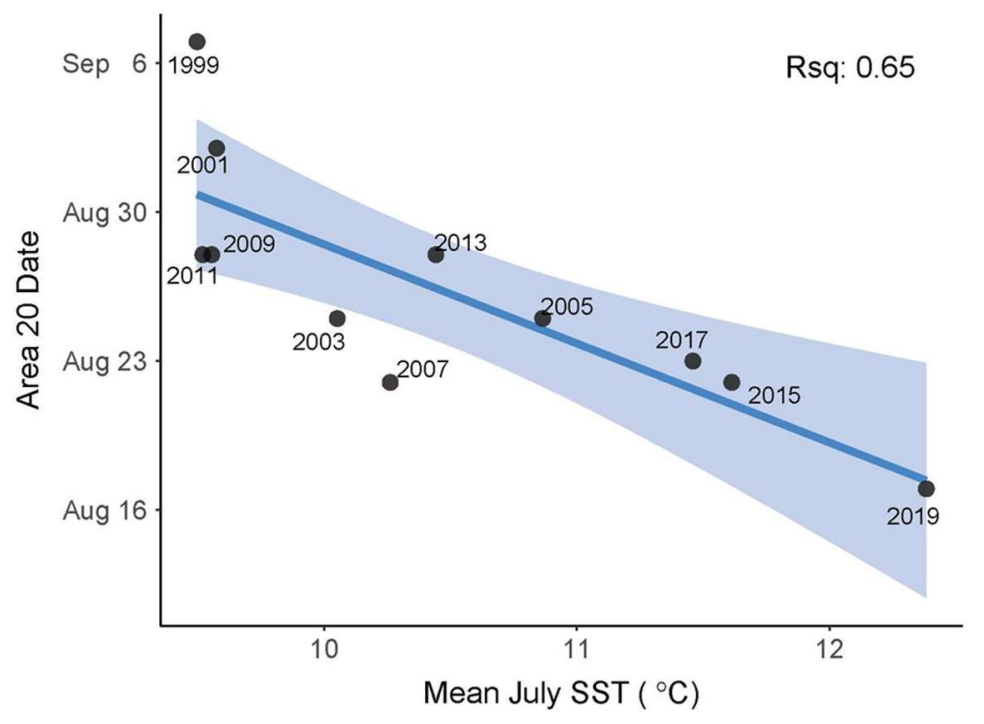

Fig. 3. The relationship between mean SST $\left({ }^{\circ} \mathrm{C}\right)$ in July of the return year at Pine Island and marine run timing. The shaded region is the $95 \%$ confidence interval.

The second method used to improve pre-season forecasts identifies environmental covariates which could explain the underlying non-stationarities in salmon abundance or behaviour. For example, DFO forecasts timing and northern diversion rates of Fraser River sockeye and pink salmon using oceanographic covariates associated with conditions experienced by returning adults during marine approach (Folkes et al. 2018). While the actual models are more complex, a simple linear regression illustrates the significant relationship between summer water temperature and the arrival timing of pink salmon to marine test fisheries (Fig. 3). DFO also incorporated 
environmental covariates into their pink salmon stock recruit model to forecast the 2021 return (DFO 2021). A simple log-linear regression between regional spring SST during the ocean entry year illustrates the potential influence of a single environmental covariate, particularly when temperatures are higher than average (Fig. 4). Restricting the historical time series greatly improved model fit and significance due to the increased frequency and magnitude of extreme sea surface temperatures, and SST anomalies, in recent years. At lower temperatures, the relationships illustrated in Fig. 3 and Fig. 4 are no longer significant. Non-linear relationships between environmental variables and salmon survival or behaviour are not unusual (Munsch et al. 2020; Eliason et al. 2010), and some variables will only become informative predictors once a certain threshold has been exceeded (Munsch et al. 2020; Satterthwaite et al. 2020). In addition, it is important to select oceanographic covariates for which a biological mechanism can be identified. Such considerations will improve the predictive capacity of the approach and reduce the probability of reliance on models for which the relationship breaks down over time (Gosselin et al. 2021).

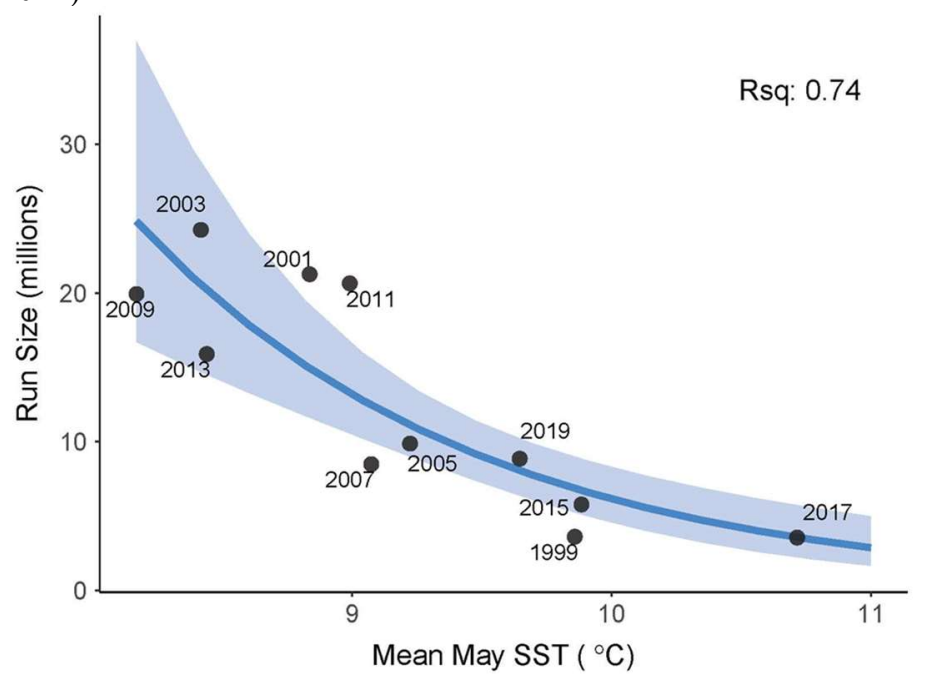

Fig. 4. The relationship between mean sea surface temperature $\left(\mathrm{SST},{ }^{\circ} \mathrm{C}\right)$ in May of the out-migrating year at Pine Island and run size. The shaded region is the $95 \%$ confidence interval.

More accurate pre-season forecasts also improve the performance of in-season stock assessment tools. For example, pre-season estimates of run size, timing, and northern diversion are used as priors in Bayesian time-density models which generate estimates of total salmon abundance and arrival timing (Michielsens and Cave 2018). The priors are updated using in-season CPUE data from marine area purse seine test fisheries to produce daily estimates of fish abundance. However, even with improved prior assumptions, low and highly variable historical catchability estimates also contribute to uncertain and/or biased in-season run sizes. For example, in 2013, an in-season run size estimate of 26 million pink salmon derived from test fishery CPUE and historical catchability estimates was later revised to an estimate of 16 million post-season - a bias of 78\% (PSC 2019b). Hydroacoustic estimates produced at a facility in the lower Fraser River (near Mission, BC, Fig. 1) provide a much more accurate assessment of daily run size, but unlike the 6-8 day migration time between marine test fisheries and the river exhibited by sockeye salmon (Michielsens and Cave 2018), pink salmon swim more slowly resulting in a two-three week offset between marine approach areas and river entry (White 1998). As a result, hydroacoustic estimates of pink salmon abundance cannot be incorporated into run reconstruction models to update test fishery catchability, or into time-density models to update estimates of total run size (Michielsens and Cave 2018) in time to inform management decisions.

Given the uncertainty in pink salmon catchability, one alternative is to adopt a simplified approach using a direct relationship between CPUE and run size. There is a significant log-linear relationship $\left(R^{2}=59 \%\right)$ between three-day average test fishery CPUE early in the run and total pink salmon run size (Fig. 5). This simple tool can be used to provide an early indication of whether the strength of the run is likely to deviate from the pre-season forecast. Alternatively, when available, commercial fishing CPUE data have also been used to estimate pink salmon abundance through the U.S. approach (PSC 2016). While data are limited, historical run reconstructions suggest that U.S. purse seine fisheries operating in the San Juan Islands (Fig. 1) have a much lower, and less variable, catchability than the seaward purse seine test fisheries (PSC 2016). When available, the commercial data can be incorporated into existing run reconstruction models and used to update the estimate of test fishery catchability. However, modelers must still use caution when the commercial fishing effort is low and/or there are few days of commercial openings as incorrect migration rate assumptions can still introduce errors into the run reconstructions. 


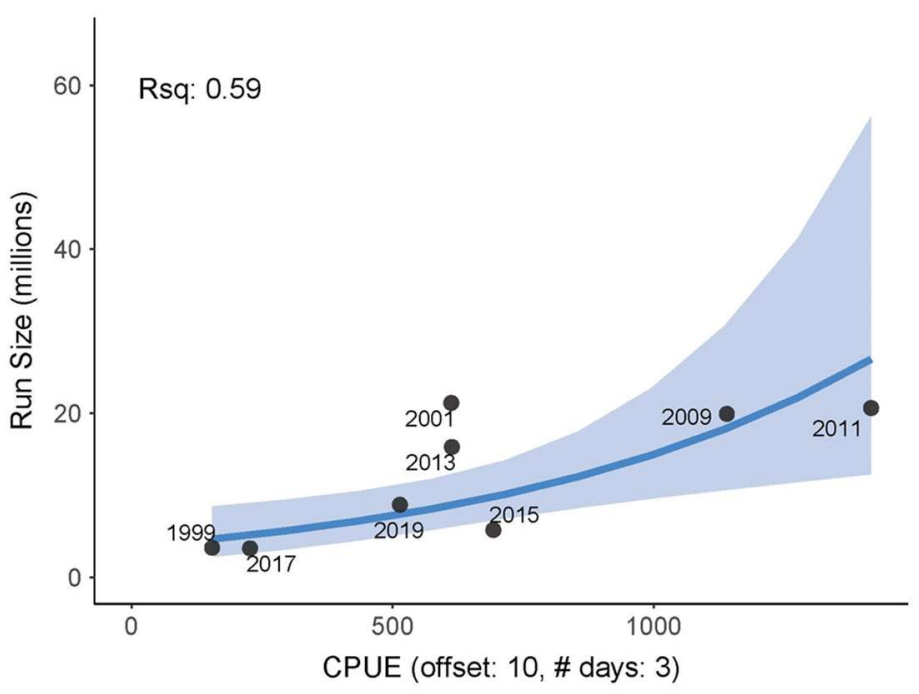

Fig. 5. The relationship between three-day average test-fishery catch per unit effort data collected tendays prior to the peak migration date and run size. The shaded region is the $95 \%$ confidence interval.

Changing environmental conditions and concurrent changes to productivity and migration behaviour of Fraser River pink salmon necessitates a re-evaluation of traditional stock assessment approaches. Updated model parameterization and use of environmental data to better predict annual timing and abundance of returns may help improve in-season assessments and increase the probability of achieving fisheries management objectives. In addition to improving prior estimates of run size and timing using environmental data, application of a suite of alternative in-season stock assessment tools and data sources are also required for developing robust estimates of pink salmon return. Modelling approaches should be iteratively re-evaluated in a retrospective framework, particularly until causal relationships between environmental covariates and salmon biology are better understood.

\section{REFERENCES}

Agha, M., J.P. Losee, M.N.C. Litz, C. Smith, J.J. Schaffler, W.S. Patton, A.M. Dufault, and G.M. Madel. 2021. Temporal patterns and ecosystem correlates of chum salmon (Oncorhynchus keta) migration phenology in the Pacific Northwest. Can. J. Fish. Aquat. Sci. doi:10.1139/cjfas-2020-0392.

Beamish, R.J., D.J. Noakes, G.A. McFarlane, L. Klyashtorin, V.V. Ivanov, and V. Kurashov. 1999. The regime concept and natural trends in the production of Pacific salmon. Can. J. Fish. Aquat. Sci. 56: 516-526. doi: 10.1139/f98-200.

Connors, B., M.J. Malick, G.T. Ruggerone, P. Rand, M. Adkison, J.R. Irvine, R. Campbell, and K. Gorman. 2020. Climate and competition influence sockeye salmon population dynamics across the Northeast Pacific Ocean. Can. J. Fish. Aquat. Sci. 77: 943-949. doi: 10.1139/cjfas-2019-0422.

Crozier, L.G., B.J. Burke, B.E. Chasco, D.L. Widener, and R.W. Zabel. 2021. Climate change threatens Chinook salmon throughout their life cycle. Comm. Bio. doi:10.1038/s42003-021-01734-w.

Dorner, B., R.M. Peterman, and S.L. Haesker. 2008. Historical trends in productivity of 120 Pacific pink, chum, and sockeye salmon stocks reconstructed by using a Kalman filter. Can. J. Fish. Aquat. Sci. 65: 1842-1866.

Eliason, E.J., T.D. Clark, M.J. Hague, L.M. Hanson, Z.S. Gallagher, K.M. Jeffries, M.K. Gale, D.A. Patterson, S.G. Hinch, and A.P. Farrell. 2010. Differences in thermal tolerance among sockeye salmon populations. Science 332: 109-112.

Fisheries and Oceans Canada (DFO). 2021. Pre-season run size forecasts for Fraser River sockeye (Oncorhynchus nerka) and pink (Oncorhynchus gorbuscha) salmon in 2021. Can. Sci. Advis. Sec. Sci. Resp. In press.

Folkes, M.J.P., R.E. Thomson, and R.A.S. Hourston. 2018. Evaluating models to forecast return timing and diversion rate of Fraser sockeye salmon. DFO Can. Sci. Advis. Sec. Res. Doc. 2017/021. 220 pp.

Gosselin, J.L., L.G. Crozier, and B.J. Burke. 2021. Shifting signals: correaltion among freshwater, marine and climatic indices often investigated in Pacific salmon studies. Ecol. Indic. 121: 107-167. doi: 10.1016/j.ecolind.2020.107167.

Heard, W.R. 1991. Life history of pink salmon (Oncorhynchus gorbuscha). In Pacific salmon life histories. Edited by C. Groot and L. Margolis. Univ. British Columbia Press, Vancouver. pp. 119-230.

Kovach, R.P., A.J. Gharrett, and D.A. Tallmon. 2012. Genetic change for earlier migration timing in a pink salmon population. Proc. R. Soc., B 279: 3870-3878. 
Litzow, M.A., L. Ciannelli, P. Puerta, J.J. Wettstein, R.R. Rykaczewski, and M. Opiekun. 2018. Non-stationary climate-salmon relationships in the Gulf of Alaska. Proc. R. Soc. B. 285: 20181855. doi:10.1098/rspb.2018.1855.

Michielsens, C., and J. Cave. 2018. In-season assessment and management of salmon stocks using a Bayesian time-density model. Can. J. Fish. Aquat. Sci. 76: 1073-1085. doi: 10.1139/cjfas-2018-0213.

Munsch, S.H., K.S. Andrews, L.G. Crozier, R. Fonner, J.L. Gosselin, C.M. Greene, C.J. Harvey, J.I. Lundin, G.R. Pess, J.F. Samhouri, and W.H. Satterthwaite. 2020. Potential for ecological nonlinearities and thresholds to inform Pacific salmon management. Ecosphere 11: 1-21.

Pac. Salmon Comm. 2016. Report of the Fraser River Panel to the Pacific Salmon Commission on the 2011 Fraser River sockeye and pink salmon fishing season. $76 \mathrm{pp}$.

Pac. Salmon Comm. 2019a. Treaty between the government of Canada and the government of the United States of America concerning Pacific salmon. Pacific Salmon Commission.

Pac. Salmon Comm. 2019b. Report of the Fraser River Panel to the Pacific Salmon Commission on the 2013 Fraser River sockeye and pink salmon fishing season. $76 \mathrm{pp}$.

Pac. Salmon Comm. 2021. Report of the Fraser River Panel to the Pacific Salmon Commission on the 2019 Fraser River sockeye and pink salmon fishing season. 93 pp.

Peterman, R.M., and B. Dorner. 2012. A widespread decrease in productivity of sockeye salmon populations in western North America. Can. J. Fish. Aquat. Sci. 69: 1255-1260. doi:10.1139/f2012-063.

Satterthwaite, W.H., K.S. Andrews, B.J. Burke, J.L. Gosselin, C.M. Greene, C.J. Harvey, S.H. Munsch, M.R. O'Farrell, J.F. Samhouri, and K.L. Sobocinski. 2020. Ecological thresholds in forecast performance for key United States West Coast Chinook salmon stocks. ICES J. Mar. Sci. 77: 1503-1515.

White, B. 1998. Fraser River pink salmon catch and exploitation patterns: 1989-1995. Pac. Salmon Comm. Tech. Rep. 10. 52 pp. 